\title{
Local Scale Displacement Fields in Grains-Structure Interactions Under Cyclic Loading: Experiments and Simulations
}

\author{
S. J. Antony $\mathbb{D} \cdot$ Zuhair Kadhim Jahanger $\mathbb{C}$
}

Received: 28 September 2018/ Accepted: 7 October 2019/Published online: 19 October 2019

(C) The Author(s) 2019

\begin{abstract}
Soils encounter cyclic loading conditions in situ, for example during the earthquakes and in the construction sequences of pavements. Investigations on the local scale displacements of the soil grain and their failure patterns under the cyclic loading conditions are relatively scarce in the literature. In this study, the local displacement fields of a dense sand layer interacting with a rigid footing under the planestrain condition are examined using both experiments and simulations. Three commonly used types of cyclic loading conditions were applied on the footing. Digital particle image velocimetry (DPIV) is used to measure the local scale displacement fields in the soil, and to understand the evolution of the failure envelopes in the sand media under the cyclic loading conditions. The experimental results are compared with corresponding finite element analysis (FEA), in which experimentally-characterised constitutive relations are fed as an
\end{abstract}

Z. K. Jahanger: Formerly, Research Scholar, School of Chemical and Process Engineering, University of Leeds, Leeds, LS2 9JT, UK.

S. J. Antony ( $\square)$

School of Chemical and Process Engineering, University of Leeds, Leeds LS2 9JT, UK

e-mail: S.J.Antony@leeds.ac.uk

Z. K. Jahanger

Department of Water Resources Engineering, College of Engineering, University of Baghdad, Al-Jadriya Campus, Baghdad, Iraq

e-mail: zk_Jahanger@coeng.uobaghdad.edu.iq input into the FEM simulations. For comparison purposes, the case of footing subjected to the quasistatic loading condition was also studied. In general, the results show a good level of agreement between the results of the experiments and simulations conducted here. Overall, relatively shallower but wider displacement fields are observed under the cyclic loading, when compared with that of the quasi-static load test. The vorticity regions are highly localized at the shear bands in the sand media under the ultimate load. The research contributes to new understanding on the local scale displacement fields and their link to the bearing capacity of the footing under the cyclic loading environments.

Keywords Cyclic loads - Strip footing - Settlement · DPIV $\cdot$ FEM $\cdot$ Soil-structure interactions

\section{Introduction}

Cyclic loadings are periodically applied on soils and foundations in situ, for example under earthquakes, machine vibrations and in the construction of foundations, railways ballast and pavements. In foundation engineering, the intensity of the applied cyclic loading $\left(q_{\text {cyc }}\right)$ is compared to the quasi-static load $\left(q_{\mathrm{s}}\right)$ of the footing using the ratio $q_{\text {cyc }} / q_{\mathrm{s}}$. Usually $q_{\text {cyc }} / q_{\mathrm{s}} \leq 0.5$. Its value in the range of $0.1-0.3$ is likely to be 
measured in many earthquakes while the ratio greater than 0.5 represents an extreme event (Das and Shin 1996; Tafreshi et al. 2011). Under the cyclic loading, foundations could experience a significant level of settlement resulting structure damages (Sabbar et al. 2016). Cyclic softening can also occur in soils due to cyclic undrained loading condition, e.g. during earthquake loading (Peralta 2010). The design of the foundations under the cyclic loadings $\left(q_{\text {cyc }}\right)$ is an essential and a challenging task to perform in the geotechnical engineer applications. Information on how soil grains displace at both local and global scales under the cyclic loading conditions are still scarce in the literature.

Peralta (2010) has defined the cyclic loading as a system of repeated loads that shows a constancy in its amplitude and the frequency. Soils and foundations could also encounter environmental cyclic loadings in practice due to the waves, wind and earthquakes. Cyclic loading can occur when using the rotating machinery, from the blasting operations and traffic construction (Shajarati et al. 2012). Traffic movements or blasting also generate vibrations of a periodic character, which could affect the nearby foundations (Terzaghi and Peck 1967). Peralta (2010) has classified the types of such loading based on the frequency as cyclic, cyclic-dynamic and dynamic (Table 1). Different theoretical and experimental methods have been used to study on the effects of the cyclic loading on the failure of the footings interacting with soil. Salem et al. (2013) have defined the cyclic loading failure of the footings interacting with the soil as the number of loading cycles required to reach liquefaction (quick condition) or to reach an axial strain of $5 \%$. A soil liquefaction phenomenon occurs when a saturated or partially saturated soil significantly loses their strength and stiffness in response to the cyclic loading, causing the sand to behave like a liquid. Andersen (2009) suggested that the failure caused by cyclic loading could be defined corresponding to either a permanent or a cyclic shear strain of $15 \%$.
Furthermore, different materials and techniques have been used to understand the mechanical behaviour of the sand bed under the cyclic loads (e.g. Raymond and Komos 1978; Das and Shin 1996; Tafreshi et al. 2011; Nguyen et al. 2014; Sabbar et al. 2016). These studies reported that excessive soil deformations are produced under cyclic loading and the strains accumulate with increase in the number of cycles, causing damage to the foundations. The cyclic loading could have a significant effect on sandy soil, which is not yet understood well. Raymond and Komos (1978) determined the relationship between the settlement of the foundation and the number of load cycles of a laboratory scale surface footings on sand subjected to cyclic loadings of low frequency. They reported a significant level of initial settlement of the footing during the first ten cycles of loading. An equilibrium response was reached after about 20,000 load cycles during which plastic strain accumulated incrementally. Tafreshi et al. (2011) have investigated the response of the circular footings supported on the sand bed under the incremental cyclic loads by using the laboratory model tests and the numerical analysis. They have shown that the value of the coefficient of elastic uniform compression (CEUC which is the elastic rebound displacement of the sand in unloading cycle) of sand increased with an increase the relative density of the sand whereas it decreased with an increase in the area of the footing (Tafreshi et al. 2011). The strength of the sand under the cyclic loading could be less than that under the quasi static loading with the same level of stress amplitude. Sabbar et al. (2016) have found that the deformation of clayey soil under the cyclic loading was less rapid because of its low permeability than in sandy soil. Furthermore, the cyclic behaviour of sandy soils is influenced by factors such as the frequency, stress level, load types and the relative density of the sand.

However, experimental observations of the local scale kinematic failure mechanisms in silica sands beneath shallow footing under the vertical cyclic

Table 1 Repeating loading of soils (Peralta 2010)

\begin{tabular}{llll}
\hline Repeated loading & Cyclic & Cyclic-dynamic & Dynamic \\
\hline Frequency & $0-1 \mathrm{~Hz}$ & $1-10 \mathrm{~Hz}$ & $>10 \mathrm{~Hz}$ \\
Strain accumulation & Mostly plastic & Plastic-elastic & Mostly elastic \\
\hline
\end{tabular}


loading are generally scare in the literature. Therefore, the current study deals with the specific case of the plane strain surface footing interacting with dense sand $\left(D_{\mathrm{r}}=76 \%\right)$ subjected to three commonly encountered types of cyclic loading. The effects of the cyclic loading are studied with the help of DPIV experiments and FEM simulations. The aim is to understand the local scale displacements and corresponding failure patterns in the dense sand under the axial cyclic loadings using DPIV experiments and using the results to validate the corresponding results of the FEM simulations.

\section{Material and Experimental Methods}

\subsection{Materials and Experimental Setup}

The sand used for the test is a relatively uniform silica sand (kiln dry sand) of grain sizes between 0.07$0.9 \mathrm{~mm}$ that is obtained in UK (Jahanger 2018). The properties of the sand were characterised according to the American Society for Testing and Materials (ASTM 1989; Head 2006). The experimentally measured particle size distribution of the sand is shown in Fig. 1, and its properties are listed in Table 2. The roundness of the grain was mostly spherical to subprismoidal $(R=0.3-0.5)$ and the angularity of the grains are characterised as angular and sub-angular (Jahanger 2018). For this, digital microscopy technique using Olympus machine was used high

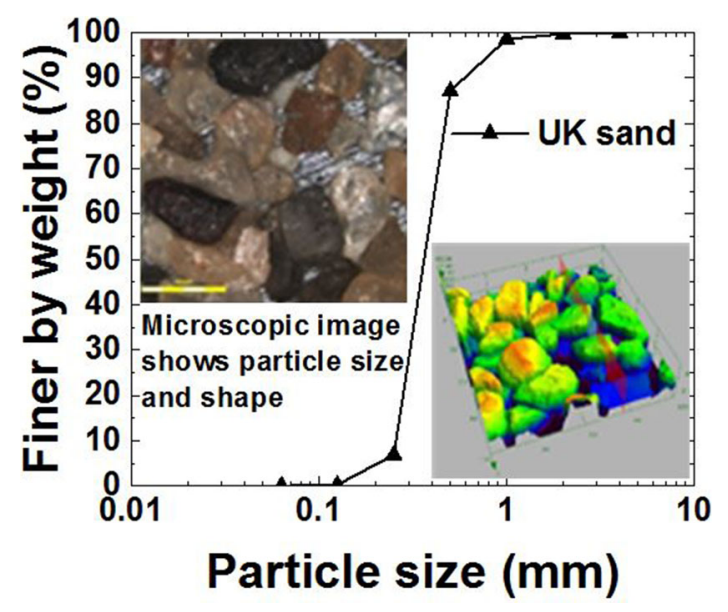

Fig. 1 Particle size distribution curve of the sand grains magnificent image on a small sand sample $(\sim 50 \mathrm{~g})$ to get the $3 \mathrm{D}$ surface imaging and micro-profile measurement with the Laser confocal microscope. It captures images from different inclinations normal to the surface where the sand sample is examined under Laser confocal lenses and constructs the 3D shape of the particles using the in-built image processing software (Jahanger et al. 2018a, b). Based on these data, the soil chosen is classified as poorly graded sand (SP) according to the Unified Soil Classification System (Cerato and Lutenegger 2007; Tafreshi et al. 2011; Dijkstra et al. 2013; Jahanger et al. 2018a, b). Such type of soils is often encountered in foundation engineering applications (Jahanger 2018).

For conducting the DPIV experiments, an aluminium planar model box with an internal dimension of $460 \mathrm{~mm} \times 300 \mathrm{~mm} \times 39 \mathrm{~mm}$ was constructed to satisfy both the optical and mechanical requirements (Fig. 2). The former requirement pertains to enabling the image recording of the grains at the front face of the box model. The front face of the box was made of a $15 \mathrm{~mm}$ thick Perspex sheet (rigid). The latter requirement is to ensure that the granular box sustains the external loading while minimising the out of plane deformation of the walls (including the front measuring side of the box) under the ultimate load. The backside of the box was made of $10 \mathrm{~mm}$ thick smooth aluminium sheet whereas the side of the box was made of aluminium frames having the dimension of $25 \mathrm{~mm} \times 39 \mathrm{~mm}$ (Fig. 2a). Hence, the dimensions of the test box were kept much greater than that of the footing (Fig. 2) to minimize any boundary effects on the grain-scale displacements during the DPIV experimental measurements. The above-mentioned experimental setup has been used successfully in the past to conduct the DPIV experiments on sand-footing interactions in sand media of different packing densities and layered sand media subjected to quasi-static loading conditions (Jahanger et al. 2018a, b). The relatively rough, rigid aluminium footing with dimensions $38 \mathrm{~mm} \times 38 \mathrm{~mm} \times 15 \mathrm{~mm}$ were used here. The footing base was relatively rough in which the ratio between the angle of interfacial friction of the rigid footing and the angle of internal friction of the sand $(\delta / \phi)$ is 0.25 . The relative roughness of the side wall of the footing $\left(\delta_{\mathrm{fw}}\right)$ in contact with Perspex wall $\left(\delta_{\mathrm{p}}\right)$; i.e., $\left(\delta_{\mathrm{p}} / \delta_{\mathrm{fw}}\right)$ was 0.09 , which was very small and negligible. 
Table 2 Physical

properties of the dense sand

Fig. 2 DPIV experiments a experimental setup, b illustrative diagram of the sand box

\begin{tabular}{llll}
\hline Type of the test & Unit & Results & Standards \\
\hline Dry density, $\gamma_{\mathrm{d}}$ & $\mathrm{kN} / \mathrm{m}^{3}$ & 16.2 & ASTM C29/C29M \\
Void ratio, $e_{\mathrm{o}}$ & & 0.62 & ASTM C29/C29M \\
Relative density, $D_{\mathrm{r}}$ & $\%$ & 76 & ASTM C128 \\
Peak friction angle, $\phi_{\text {peak }}$ & $\circ$ & 44.8 & ASTM D4767 \\
Maximum void ratio, $e_{\text {max }}$ & & 0.83 & ASTM C29/C29M \\
Minimum void ratio, $e_{\text {min }}$ & & 0.58 & ASTM C29/C29M \\
Mean grain size, $D_{50}$ & $\mathrm{~mm}$ & 0.37 & ASTM D421 \\
Uniformity coefficient, $C_{\mathrm{U}}$ & & 1.55 & ASTM D2487 \\
Coefficient of curvature, $C_{\mathrm{C}}$ & & 0.93 & ASTM D2487 \\
Roundness, $R$ & & $0.3-0.5$ & ASTM D2488 \\
\hline
\end{tabular}
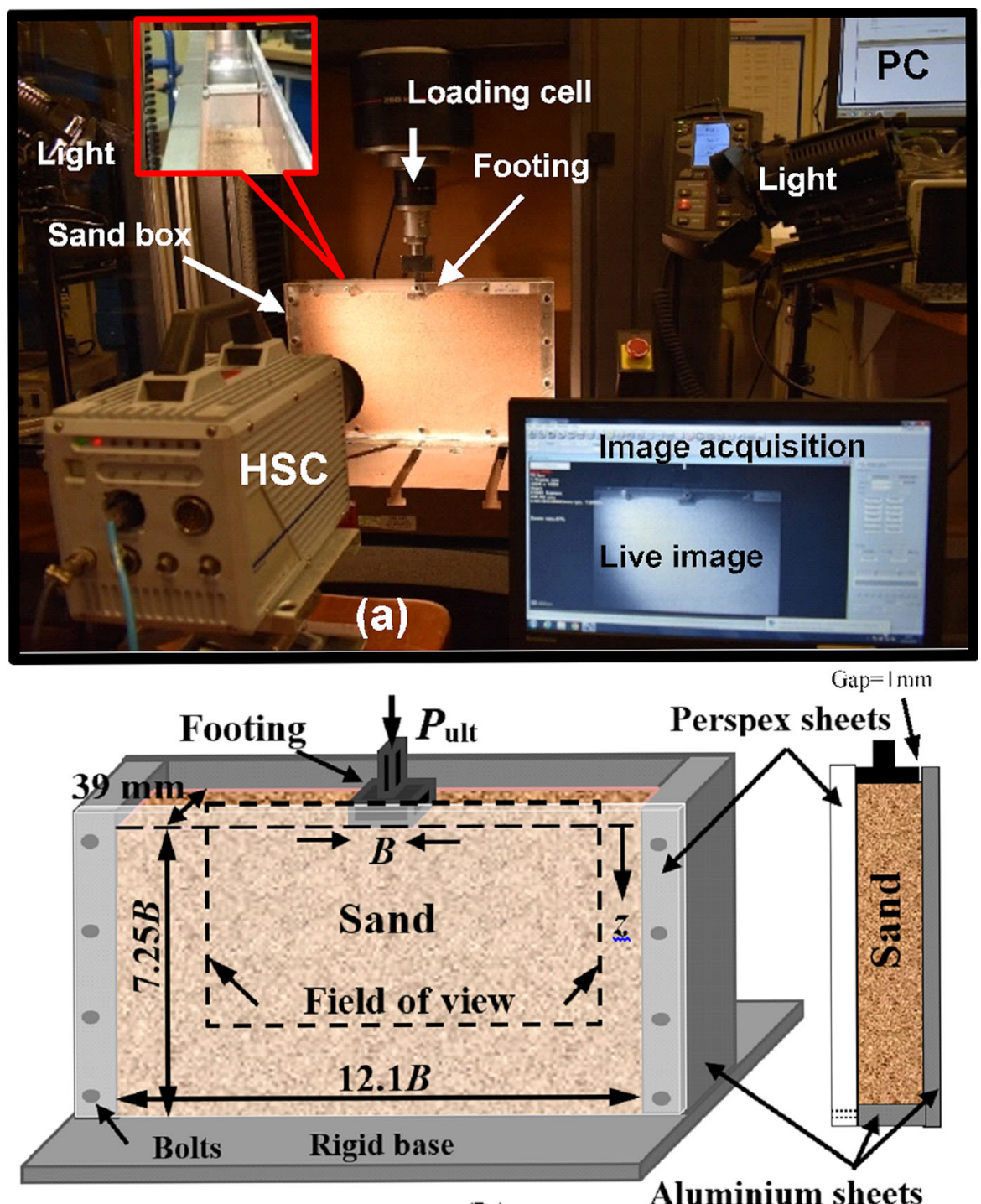

(b) 
The ratio of the width of the footing $(B)$ to the mean grain size $D_{50}$; i.e., $B / D_{50} \geq 100$, [which is within the permissible limit to minimise any size effect arising from the relative sizes of the footing and the sand grains (White et al. 2004; Dijkstra, et al. 2013; Jahanger et al. 2018a, b)]. A small gap of $1 \mathrm{~mm}$ was set between the rear surface of the footing and the rear side of the aluminium wall to minimise the effects of any resisting frictional forces between these surfaces (back side of the box, whereas the DPIV measurements are conducted on the front side of the box). It was verified that no significant leakage of the grains occurred through this gap during the tests. The planar box filled with sand is placed stationary while the footing model was indented on the surface of the sand packing (Fig. 2). Figure 2 shows the complete setup of the footing test in the current study, which includes a high-speed camera HSC (Photron Fastcam SA5) in front of the planar model placed in an Instron $5 \mathrm{kN}$ loading machine (Instron No. 5985L3398). The HSC with an allowable frame speeds up to 100000 frames per second (fps) was used.

\subsection{Preparation of the Dense Sand Packing}

The sand was prepared in homogeneous dense packing of relative density $D_{\mathrm{r}}=76 \%$, using the falling pouring technique method at a constant rate based on Kumar and Bhoi (2009) and Jahanger et al. (2018a, b), into five layers of $\sim 55 \mathrm{~mm}$ thick each. The mass of sand grains laid in the box correspond to the required height and the packing density of the sand. Then the sand layer was compacted using 60 blows per layer in $35 \mathrm{~mm}$ lifts each with a $16 \mathrm{~cm}^{2}$ compaction tamper of $1.10 \mathrm{~kg}(10.3 \mathrm{~N})$ weight designed for this purpose, which corresponds to a theoretical energy of $0.36 \mathrm{Nm}$ (J) (Cerato and Lutenegger 2007; Jahanger et al. 2018a, b; Jahanger 2018). These sand packing were prepared directly beneath the loading plate of the loading machine to minimise any disturbances of the sand grains before the tests. The top surface of the sand layer was gently levelled off using a guided hand scraper designed for this purpose. The footing was then placed symmetrically on the surface of the compacted dense sand layer (Fig. 2).

\subsection{Cyclic Loading Types and Test Programme}

Quasi-static and cyclic loading patterns were performed under three types of strain-controlled tests (Fig. 3). Details of the corresponding loading levels are presented in Table 3. For studying the mechanical response of the footing-sand interactions, experiments were carried out to measure the quasi-static ultimate bearing capacity $\left(q_{\mathrm{ult}}\right)$ and the corresponding settlement of the footing $\left(S_{\mathrm{u}}\right)$. The quasi-static load was applied on the footing at a slow rate $(0.05 \mathrm{~mm} / \mathrm{s})$ and up to $10 \mathrm{~mm}$ using the Instron machine with $0.1 \mathrm{~N}$ resolution (Fig. 2). The macroscopic load-settlement relations of the footing on the dense sand were measured at a frequency of $1 \mathrm{~Hz}$.

The cyclic load experiments were conducted using the Instron machine for the three types of the cyclic loading patterns to measure the cyclic ultimate bearing capacity $\left(q_{\text {ultcyc }}\right)$ and the corresponding settlement of the footing $\left(S_{\text {ucyc }}\right)$ (Table 3$)$. These are defined here to simulate different types of the machine's cyclic loads, such as type 1 cyclic load selected in which the loading history consists of stepwise increasing load cycles (Fig. 3a). Type 2 cyclic load was selected based on the cyclic plate loading test (PLT) in which the amplitudes increase with the increase of the cycles (Tafreshi et al. 2011). Type 3 of cyclic loading has staggered pattern that the amplitude of the same magnitude was used in two steps to simulate loads on the footing (Asakereh et al. 2013).

Before applying the cyclic settlement $\left(S_{\text {cyc }}\right)$, the initial static settlement $\left(S_{\mathrm{i}}\right)$ was applied (Tafreshi et al. 2011). The tests were conducted by first applying the initial static settlement, $S=S_{\mathrm{i}}=2 \mathrm{~mm}$ corresponding to an initial static stress $\mathrm{q}=q_{\mathrm{s}}$, on the footing (Fig. 3a). The allowable load of the dense sand bed was first applied under the initial static settlement of $S_{\mathrm{i}}=2 \mathrm{~mm}$. Then after the cyclic loadings were applied using a sinusoidal loading. The amount of the load on the footing was then varied between the $S=S_{\mathrm{i}}$ and $S=S_{\mathrm{i}}+S_{\text {cyc }}$ with a frequency of $0.23 \mathrm{~Hz}$, $0.35 \mathrm{~Hz}$ and $0.40 \mathrm{~Hz}$ for cyclic loading type 1-3 respectively. The amplitude was increased incrementally at $1 \mathrm{~mm}$ per each cycle for type 1-2 but increased at $5 \mathrm{~mm}$ and $3 \mathrm{~mm}$ during first and second stages respectively for cyclic loading type 3 . The cycles of the loading, unloading and reloading are continued until the ultimate load was reached. The resulting loading patterns are shown in Fig. 3. Thus, the cyclic 


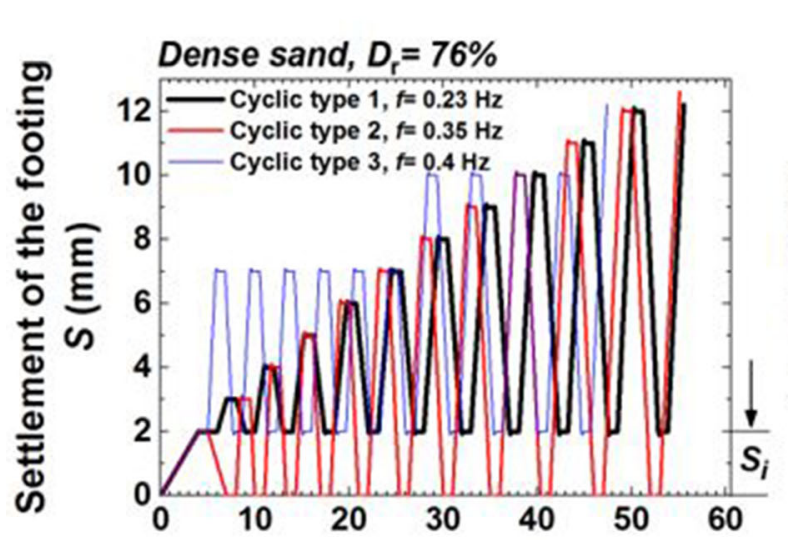

(a)
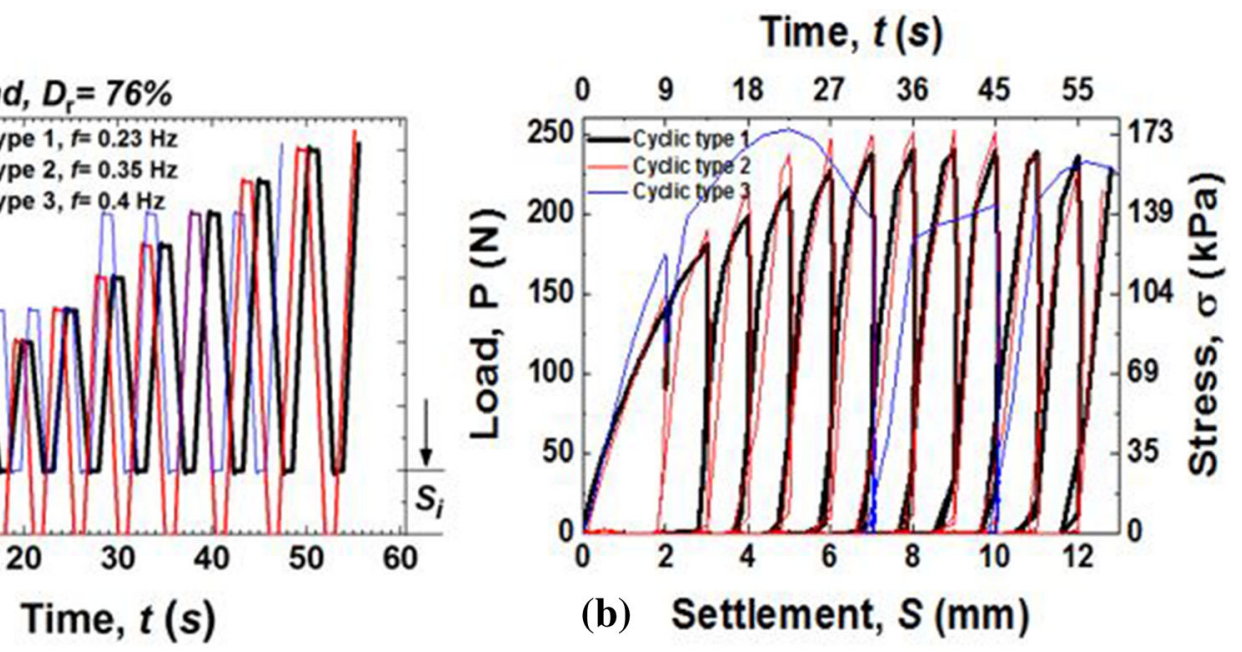

(b) Settlement, $s(\mathrm{~mm})$

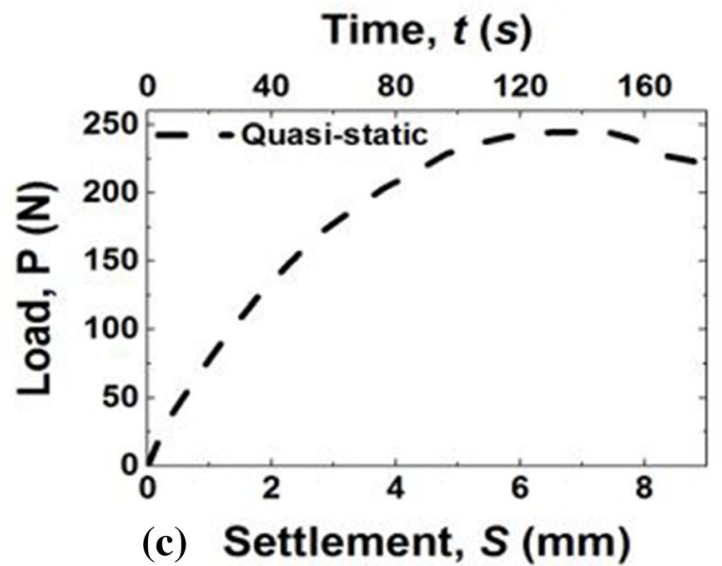

Fig. 3 Pattern of cyclic and quasi-static loadings applied to the footing

Table 3 Details of the laboratory model tests

\begin{tabular}{lll}
\hline Tests & $q_{\mathrm{s}} / q_{\mathrm{ult}}$ & $q_{\mathrm{ultcyc}} / q_{\mathrm{ult}}$ \\
\hline Quasi-static & - & - \\
Type 1 & 0.59 & 0.155 \\
Type 2 & 0.59 & 0.165 \\
Type 3 & 0.65 & 0.09 \\
\hline
\end{tabular}

stress intensity varied between zero and the accumulative cyclic load (stress) $q_{\text {cyc }}$. Therefore, the footing was allowed to rebound to zero stress or initial static stress $\left(q_{\mathrm{s}}\right)$ depending on the applied types of the cyclic load.

\subsection{Digital Particle Image Velocimetry (DPIV) Analysis}

DPIV pertains to the digital platform of particle image velocimetry, PIV (Jahanger et al. 2018a, b). PIV is often used in the field of fluid mechanics to track the motion of particles in the fluid flow using the tracer particles (Adrian 1991). Many researchers have applied PIV to study the displacement and (/or) strain distribution in some cases of granular packing under quasi-static loading conditions (Hamm et al. 2011; O'Loughlin and Lehane 2010; Murthy et al. 2012; Jahanger et al. 2016; Jahanger and Antony 2017a, b; Jahanger et al. 2018a, b; Jahanger 2018). However, such an analysis for cyclic loading is not widely reported yet, an aspect addressed in the current work. 
An axial compression loading (q) was applied slowly on the footing (frequency $<1.0$ ) using the Instron machine (Fig. 2). The macroscopic loadsettlements of the footing on the dense sand were recorded from the tests. In the present study, the DPIV camera lens was focused normal to the plane of the footing structures-soil interface region of $\sim 273 \mathrm{~mm}$ $\times 154 \mathrm{~mm}$ and two light sources were used to illuminate the rig (Fig. 2). This was further subdivided into 129,600 interrogation areas (IA) of minimum of $4 \times 4$ pixels each covering a zone of about $0.57 \mathrm{~mm} \times 0.57 \mathrm{~mm}$ which contains a minimum of 3 grains in each IA. The resolution of the images was $1920 \times 1080$ pixels. This corresponds to a scale of $\sim 0.14 \mathrm{~mm}$ per pixel in this study. Hence, the DPIV experimental measurements made here are at the local-scale. However, in view of the cyclic loading condition and the limited storage capacity of the acquisition system, recording the images at $250 \mathrm{fps}$ was found to be adequate until the sand media reached the failure stage (up to $60 \mathrm{~s}$ recording in real time; $250 \mathrm{fps}$ has a spatial resolution between $0.028-$ $0.0001 \mathrm{~mm})$.

In this study, Dynamic Studio Software Platform (DSSP) was used to analyse the digital images acquired during test using DPIV (DantecDynamics 2013). The DSSP provides a range of techniques for characterising the particle motions, making it convenient for making advanced scientific image-based measurements (DantecDynamics 2013). This functionality built in the DSSP was used to analyse the digital frames of the grains between two successive images, and to calculate the velocity vectors of the grains and their evolution under loading (Albaraki and Antony 2014; Jahanger and Antony 2017a, b; Jahanger et al. 2018a, b; Jahanger 2018). The distribution of velocity vectors of the grains was examined using an adaptive IA (interrogation area) of maximum size $16 \times 16$ pixels ( $\sim 36$ particles). The mean number of particles per maximum IA should vary between 10 and 25 (DantecDynamics 2013). The convergence limit of 0.01 pixel was employed in the image analysis (DantecDynamics 2013). A typical mean size of sand grain was represented by a patch of $3 \times 3$ pixels to minimise any error in the PIV measurements (Gollin et al. 2017). Each of these patches was tracked using an adaptive PIV method to identify the deformation field of sand grains between successive images, to a measurement precision of $0.014 \mathrm{~mm}$ for the field of view used during these experiments. The adaptive PIV iteratively adjust the size and the shape of the individual IA in order to adapt to local seeding densities (seeding with particles to create colour coded upon which image processing can operate) and flow gradients (DantecDynamics 2013; Jahanger et al. 2016; Gollin et al. 2017; Jahanger and Antony 2017a, b; Jahanger et al. 2018a, b). This space-pixel dimension of the measurement was calibrated by printing a known scale on the test box along the horizontal and vertical directions. The variations in the image scale in both horizontal and vertical direction (fish eyes) were not significantly different. Furthermore, texture enhancement of the sand with coloured grains was adopted to increase the accuracy of the image correlation. The tests were repeated at least twice to verify the repeatability and the consistency of the test data (Kumar and Bhoi 2009; Jahanger et al. 2018a, b). The displacement measures i.e. horizontal displacement $\left(S_{h}\right)$, vertical displacement $\left(S_{v}\right)$, and the resultant displacement $\left(S_{R}\right)$ were calculated under a given load in total. It is worth mentioning that, the displacement fields between the reference image at zero load $(\mathrm{q}=0)$ and the image at the ultimate static load $q_{\text {ult }}$ and at maximum loading per each cycle of the cyclic loading test has calculated.

\subsection{Scale Effects and Limitations}

It is acknowledged that the scale effects of the footing model could affect the estimations of their strength characteristics, however this could be minimized (Jahanger et al. 2018a, b). Though small-scale models are widely used to investigate the behavior of the fullscale foundation in practice, there could be some differences between the results of the experiments using laboratory models and the prototype (Vesic 1973, Liu and Evett 2004). In addition, it should be noted that the experimental results were obtained for only one size of the width of the footing. Although the settlement of footings could depend on their actual width for a given soil (Das 2018), the ultimate bearing capacity of sand is less dependent on footing width $(B)$ when $B$ is less than $1 \mathrm{~m}$ as reported by Terzaghi and Peck (1967). To minimize the scaling effect, it was suggested that the packing density of the tested sample should not pertain too close to its maximum void ratio $\left(e_{\max }\right)$ and minimum void ratio $\left(e_{\min }\right)$ (Altaee and 
Fellenius 1994). These suggestions were accounted for in the current study to minimise the scale effects.

Furthermore, Jahanger and Antony (2017b) have applied the DPIV in the analysis of scale effects in sand of different packings interacting with footing. They reported scale effect for the strip surface footing interacting with sand packings. The bearing capacity factors $\left(N_{\gamma}\right)$ rapidly decreased from 98.5, 246 and 443 to $13.6,60$ and 52 for footing widths increased from $0.038 \mathrm{~m}$ to $B=0.65 \mathrm{~m}$ for loose, medium-dense and dense sand respectively, after which there is no substantial decrease in the $N_{\gamma}$. It means that the scale effects are minimised beyond certain sizes of the footing. Even though the scaling effects cannot be completely ignored in small-scale test and the test results, by minimising its effects, the study provides useful insights on the local displacement patterns of the sand under the loading conditions considered here. Furthermore, the authors wish to point out that, in the case of strip footings used in practice, 3D condition could exist around the ends of the strip footings even if the footing is long. However, for most parts of long strip footings, plane strain condition could exist (Bowles 1996; O'Loughlin and Lehane 2010; Jahanger et al. 2018a, b) as assumed in the current 2D plane strain experiments (Raymond 2002; Jahanger et al. 2018a, b).

\section{Finite Element Method Simulations}

To simulate the mechanical properties of granular media under external loading, discrete element method (DEM) (Cundall and strack 1979) and finite element method (FEM) (Potts and Zdravkovic 2001) are commonly used in the literature. Both the methods have advantages and some disadvantages. In DEM, the assemblies of granular materials are modelled as individual grains with a particular type of interparticle interactions, ranging from a simple linear spring-dashpot model to the more complex theories of contact mechanics (Thornton and Antony 1998). The method models the interactions between the neighboring particles as a dynamic process depending on the loading conditions. The method enables to study the evolution of the movement of the grains and the stress distribution characteristics of the inter-granular contacts at the local scale (Antony 2007). However, simulating the granular interactions either to the real- scales or the commonly used lab-scale dimensions of footing-sand interactions are too time consuming and computationally expensive. On the other hand, FEM simulations are more suited to handle large-scale problems, but inherently the granular media is usually considered as a continuum with a given type of the constitutive relations of the sand media (Jahanger 2018). It is not yet well known on to what extent the local-scale displacements of sand media agree with the local-scale experimental measurements of the displacements of the sand grains in footing-sand interactions, for example using DPIV as in this study. This aspect is investigated in the present study using FEM simulations as follows.

In this study, using ANSYS workbench 17.2 (ANSYS 2016), a non-linear elastic FEM simulation have been conducted corresponding to the experimental conditions. ANSYS software was used to create a two-dimensional solid geometry of the footing and the soil. The soil and the footing were modelled under plane strain condition. The discretization of the footing and the soil layer were done using an eightnodded quadratic solid element having two degrees of freedom at each node, i.e., translations in the nodal $\mathrm{x}$ and $y$ directions, as illustrated in Fig. 4. The size of the single-elemental geometry is also shown in Fig. 4. The nodes and element numbers in the soil body are equal to 11,500 and 3730 respectively. The strip footing was discretised using nodes and element numbers 228 and 76 respectively. Though not presented here, we had verified that, the level of elemental discretisation used here (Fig. 4) is adequate to get a good level of convergence at the end of the applied load. Also, the sizing of the mesh (bias) was chosen to maintain the same aspect ratio of the elements of the footing and the soil at the interface region. An adaptive FE mesh generation (Lee 2015) was applied at the footing-soil interface where the largest strains and stresses could be expected. It should be mentioned that the Skewness mesh metric (a measure of mesh quality) of $\sim 6 \times 10^{-6}$ value was achieved which is regarded as well acceptable (Lee 2015; Jahanger et al. 2018a, b; Jahanger 2018).

The simulations were held under identical boundary conditions for the quasi-static and the cyclic load tests as in the DPIV experiments. In the simulation, the bottom most nodes were fully constrained in both the horizontal and vertical directions $\left(S_{h}=S_{v}=0\right)$ (Fig. 4). The far side of the assembly was free to 
Fig. 4 (left) Chosen domain and boundary conditions (right) finite element mesh, and element enlarged
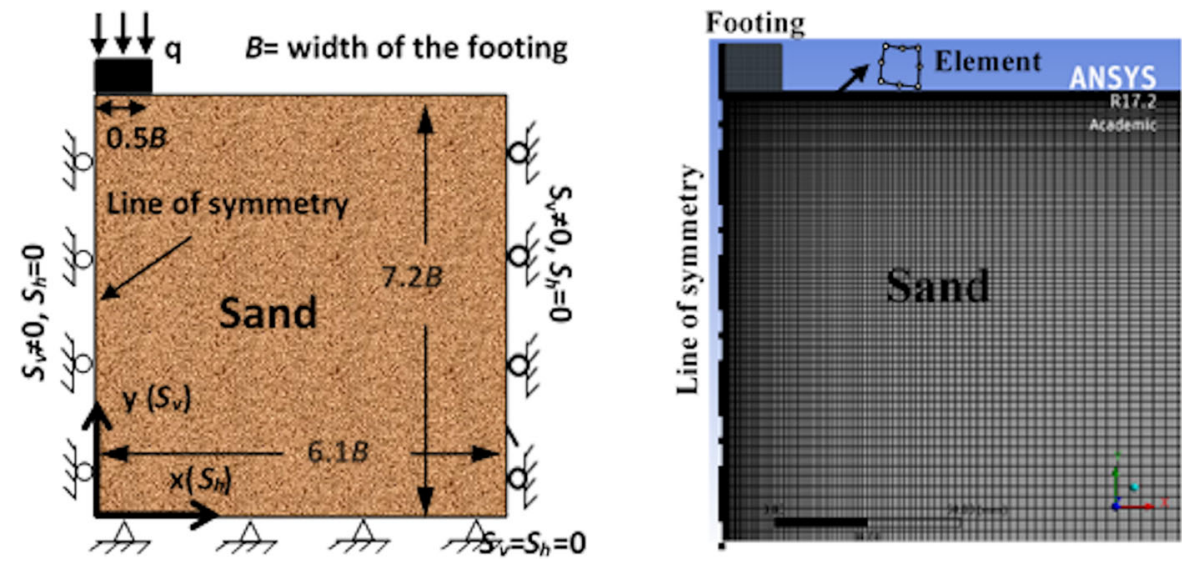

move in the vertical direction $\left(S_{v} \neq 0\right)$ and fully constrained in the horizontal direction $\left(S_{h}=0\right)$ (Mosadegh and Nikraz 2015; Jahanger et al. 2018a, b). A line of symmetry is used along the footing centre line $\left(S_{h}=0, S_{v} \neq 0\right)$. The contact areas between the footing and the dense sand were modelled as a relatively rough surface (frictional) with the interface friction coefficient $=0.25$ and corresponding to the experimental study of Kumar and Kouzer (2007), Armin et al. (2014), Gordan et al. (2014), Lee (2015), Jahanger et al. (2018a, b). The interaction involves displacements and sliding of the elements in the contact area, which introduces non-linearity to the system.

The material model used here to describe the nonlinear behaviour is based on the experimentally characterised bulk stress (load/area)-strain $(S / B)$ relationship corresponding to the hardening part of the load-displacement curves of the dense sand packing (Fig. 3b). These were discretised into a large number of linear segments and fed as user-defined digital input (ANSYS 2016; Lee 2015; Jahanger et al. 2018a, b; Jahanger 2018) in small increments as presented in Fig. 3a. Furthermore, the experimentally measured material physical properties for dense sand were used as input to the simulations including bulk density $(\gamma)$, initial modulus of elasticity ( $E=50 \mathrm{MPa})$, Poisson's ratio $(v=0.35)$ as suggested by Das $(2009)$. In the present analysis, ANSYS used the multilinear isotropic hardening (plasticity) stress-strain relationship to model sand (Lee 2015; Jahanger et al. 2018a, b; Jahanger 2018). Geometrical non-linearity was also allowed in the simulation by enabling the large deformation (ANSYS 2016). The axial loading was applied for the three types of the loads considered here on the rigid footing geometry elements (of length $0.5 B$, Fig. 4) of time step in the range of $0.001-0.1 \mathrm{~s}$ to achieve the convergence requirements of the simulation (ANSYS 2016). The total duration of the static and loading cycle pertains to about $20 \mathrm{~min}$. It is worth mentioning that such an approach was earlier applied successfully to analyse the interaction behaviour of strip footing-sand interactions under the quasi-static loading (Jahanger et al. 2018a, b). The evolution of the nodal displacement characteristics in the solid geometry (depicting the sand packing) was tracked under different loading levels and compared with corresponding DPIV measures later.

\section{Results and Discussion}

\subsection{Quasi-static Tests}

For the purpose of comparison with the cyclic loading tests, the results of the load-settlement behaviour under the quasi-static loading condition is incorporated in Fig. 3c. From this, the ultimate bearing capacity of the soil $\left(q_{\mathrm{ult}}\right)$ and the corresponding settlement of the model footing $\left(S_{\mathrm{u}}\right)$ could be evaluated (Jahanger et al. 2018a, b). The ratio of the ultimate vertical settlement of the footing $\left(S_{\mathrm{u}}\right)$ to the width of the footing $(B)$, i.e., $S_{\mathrm{u}} / B$ was obtained as $11.7 \%$. It was also verified that this agreed very well with the corresponding FEM results of $12 \%$ in this study. By repeating the experiments, it was also verified that the variability in the experimental results between the tests were less than $10 \%$ and practically 
acceptable (Tafreshi et al. 2011; Jahanger et al. 2018a, b).

\subsection{Cyclic Load Tests}

The ultimate cyclic bearing capacity $\left(q_{\text {ultcyc }}\right)$ occurs at higher settlement value compared to the quasi-static experiment conducted here (Fig. 3b) in agreement with some previous studies. For example, $q_{\text {ultcyc }}$ for the case of cyclic type 2 loading agrees with the previous quasi-static and cyclic loading of sand (Tafreshi et al. 2011; Tafreshi and Dawson 2012). In general, a well-defined peak is obtained in the cases of the cyclic loading tests and the failure corresponds to general shear failure (Terzaghi 1943). Mostly, a peak value of ultimate load and corresponding settlement response under the cyclic loading was obtained within the first 7 cycles of loading. The ratio of ultimate vertical cyclic settlement $\left(S_{\text {ucyc }}\right)$ under the ultimate cyclic load to $B, S_{\text {ucyc }} / B$ is $\sim 13-18 \%$ in all cases of the cyclic loading considered in the study. This ratio is about $11.8 \%$ in the case of quasi-static loading test (Fig. 3c). These measures are consistent with the results reported earlier for example, by Andersen (2009). The slight increase of this ratio of $S_{\text {ucyc }} / B$ in the case of cyclic loading experiments could be due to the potential increase in the soil stiffness due to the movement of the grains as sand accommodates relatively large strain in the soil beneath the footing under the ultimate load (Tafreshi et al. 2011) (Fig. 3b).

The test results here also suggest that the amplitude of the cyclic loading has a significant effect on both the vertical and horizontal permanent deformation behaviors of the sand in which the deformations increase with the increase in the amplitude (Asakereh et al. 2013). It is worth mentioning that the ultimate load of the soil is a function of the amplitude and the frequency of the cyclic loads (Das 2018). The CEUC (Tafreshi et al. 2011) was estimated as $0.2-0.25 \mathrm{~mm}$ for all unloading stages under all types of cyclic loading considered in this study. These results imply that the CEUC is not much dependent on the type of loading here (Tafreshi et al. 2011).
4.3 Local Displacements Obtained from the PIV Analysis

\subsubsection{Mean Resultant Displacement Vector Fields}

Figure 5 presents the DPIV based measures of the mean resultant displacement (with the direction in which they act) under the ultimate load. However, the results are presented in two panels for each type of loading in which the scalar contours of the vertical and horizontal displacements are superimposed on the resultant displacement vector maps for the purposes of comparison. This visualization illustrates whether horizontal or vertical soil displacements dominate the failure mechanism mobilised in the sand media under the cyclic loads. We observe that the displacement fields are quite different for the cyclic loading condition when compared with that of the quasi-static loading (Fig. 5). Under the ultimate load, approximately a combined rectangular-triangular wedge of dead zone [with a constant amount of resultant displacement of the grains but has the highest magnitude of vertical displacement (Fig. 5)] is formed beneath the base of the footing in all cases of loadings. It is clear that the dead zone is fairly in rectangular shape immediately beneath the footing and followed by a triangular wedge zone.

It is worth mentioning that the dead zone does not mean that the grains are not moving at all but move as a block of grains with almost the same magnitude of displacement (Jahanger et al. 2018a, b). In granular mechanics, the dead-zone is characterised by the block of materials beneath the indenting objects with the granular materials and moving as if they are continuous extension of the indenter, i.e., no slip at the footing-granular interface. The maximum depth of this wedge zone under the ultimate load is equal to about $0.6 B, 0.8 B, 0.7 B$ and $0.95 B$ for the quasi-static, and the loading types 1-3 respectively. The relatively higher value of the resultant displacement occurs in the case of footing subjected to the type 3 loading. This also correlates to the relatively higher value of the ultimate load for this case as presented in Fig. 5.

As seen in Fig. 5, there is considerably more horizontal displacement in the sand due to the cyclic loads than in the quasi-static load where the vertical soil displacements tend to dominate. Type 3 loading contributes to increase the ultimate bearing capacity through significantly changing the geometry of the 
Distance from footing centre/ $B$

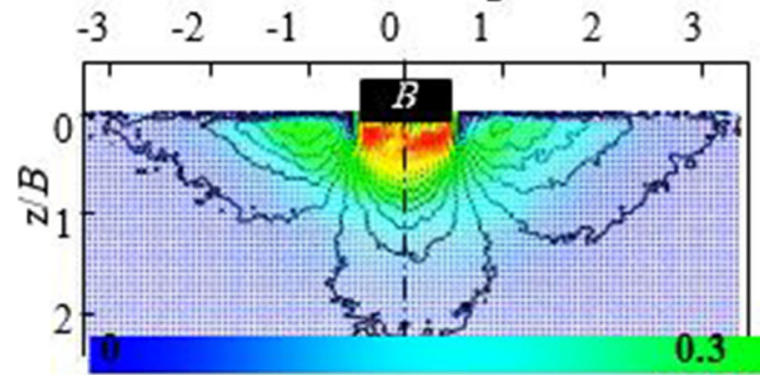

Distance from footing centre/ $B$

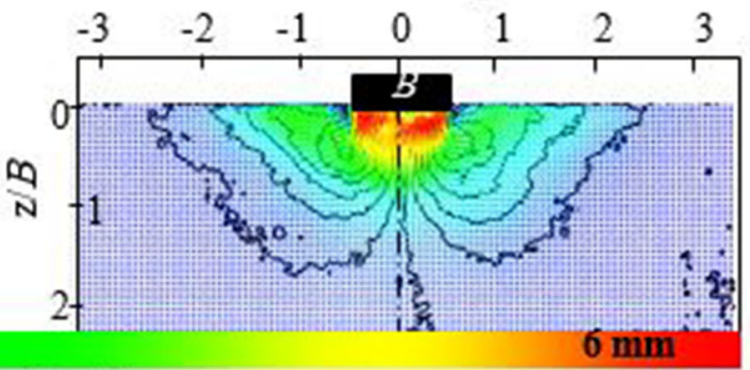

(a) Quasi-static

Distance from footing centre/ $B$

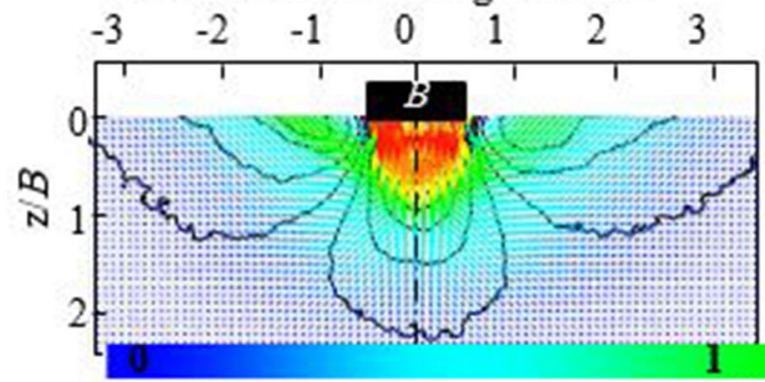

(b) Type 1
Distance from footing centre $/ B$

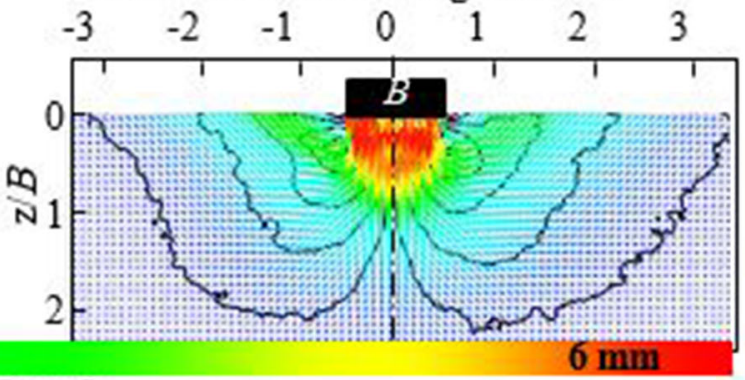

Distance from footing centre/B

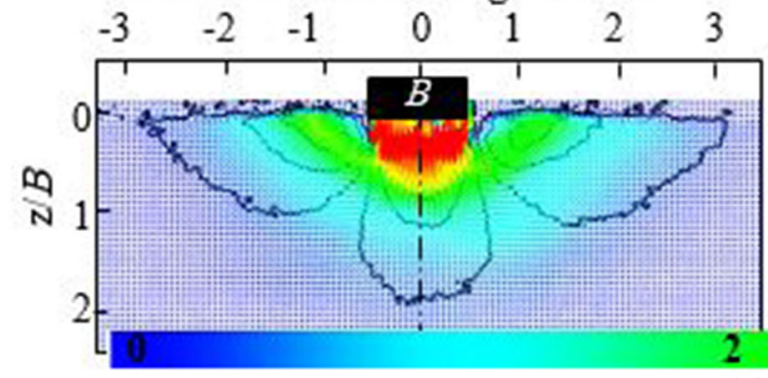

(c) Type 2

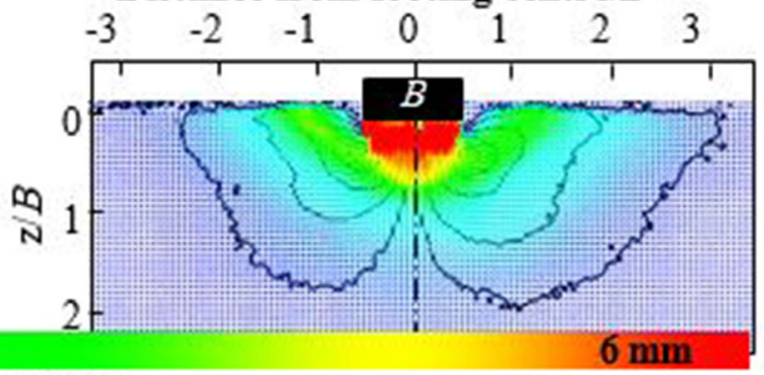

Distance from footing centre/ $B$

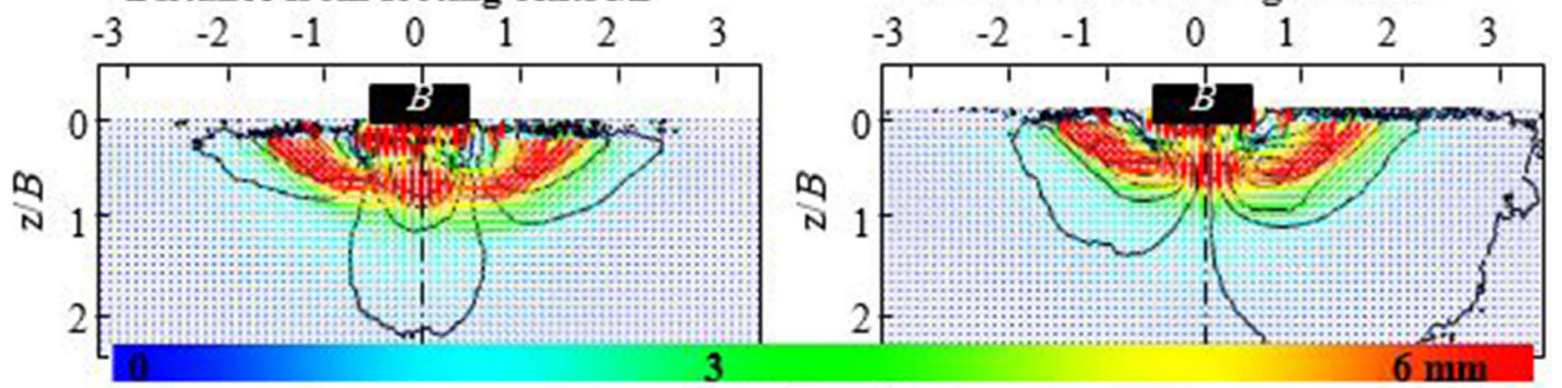

(d) Type 3

Fig. 5 Map of the mean resultant displacement vector under the ultimate load in which scalar contours of displacements are superimposed: (left) vertical displacement (right) horizontal displacement 
failure envelopes (Fig. 5). This is consistent in that a 'general shear' type failure mechanism is more dominant in the dense sands bed under the loading conditions considered here. In general, the failure patterns correspond to the conventional rigid-plastic Terzaghi's failure wedges (Fig. 5) in the analysis of foundations (Terzaghi 1943). The boundaries of the zone of plastic flow under the failure load profiled here using the DPIV are significantly similar to such intuitive diagrams suggested by Terzaghi's in 1940s (Terzaghi 1943). In general, the vertical displacement component significantly diminished in magnitude at a depth of $z / B>2$ for all types of loading.

\subsubsection{Vorticity Profiles}

In order to further characterise the displacement patterns under the ultimate load and under the cyclic loading, the mobilised vorticity zones, i.e., the highly rotational flow regions during the compression of the footing in the dense sand are investigated by plotting the vorticity $\left(\omega_{z}\right)$ profiles for all loading cases and presented in Fig. 6. It is worth mentioning that for a planar data (2D), only the rotation around the z-axis is determined (DantecDynamics 2013) as:

$\omega_{z}=\left(\partial V_{v} / \partial x\right)-\left(\partial V_{h} / \partial y\right)$ where $\partial V_{v} / \partial x$ is the gradient of vertical velocity in the $\mathrm{x}$-direction and $\partial V_{h} / \partial y$ is the gradient of horizontal velocity in the $y$-direction. It can be observed that the localized vorticity regions are developed more strongly around the corners of the footing under the ultimate load. This localization of vorticity is a result of concentration of the displacement at the corners of the footing, influenced by the rotational movement of the grains in this region (Murthy et al. 2012; Jahanger et al. 2018a, b). Previous studies suggested that the highly localised vorticity regions could correlate to the shear bands (Hamm et al. 2011). According to Jahanger et al. (2018a), in reality, local structural non-homogeneities of the grains could develop under the ultimate load and this subsequently triggers the non-symmetrical flow of grain (post-failure). Therefore, it is interesting to note that, the shear band profile is not exactly symmetrical in the dense sand bed even under the symmetric cyclic loading condition applied on the footing.

\subsubsection{Distribution of the Maximum Shear Strain Rate Under the Ultimate Load}

The maximum shear strain rate fields are derived from the displacement fields and presented in Fig. 7 to explore the failure envelope of dense sand under the
Fig. 6 Average vorticity under the ultimate load for the quasi-static and cyclic test

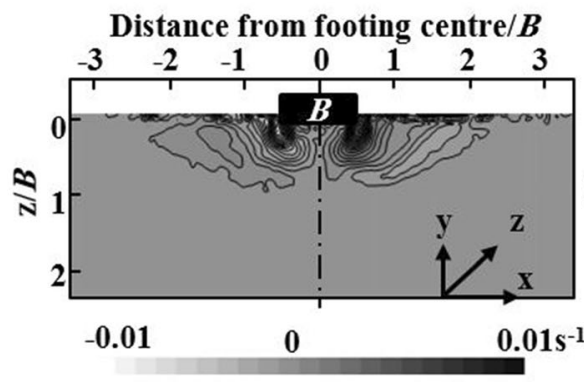

(a) Quasi-static

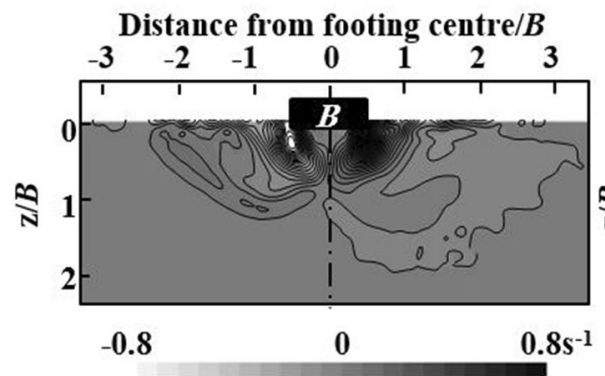

(c) Type 2

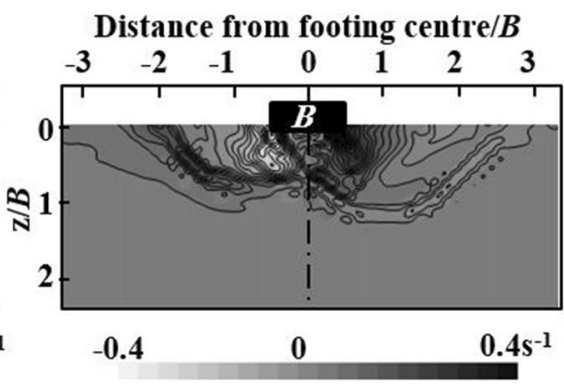

(b) Type 1

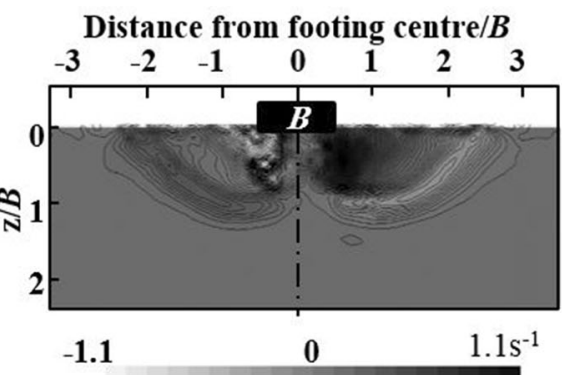

(d) Type 3 
Fig. 7 Maximum shear strain rate fields under the ultimate load for the quasistatic and cyclic tests

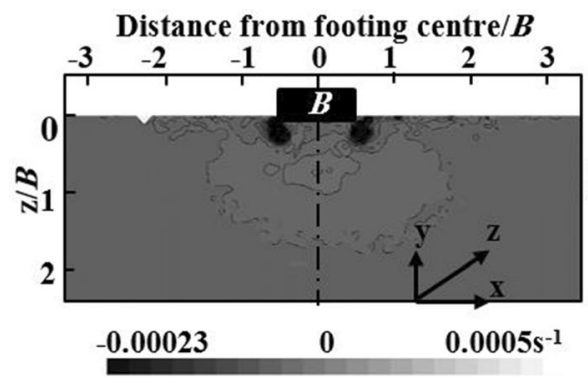

(a) Quasi-static

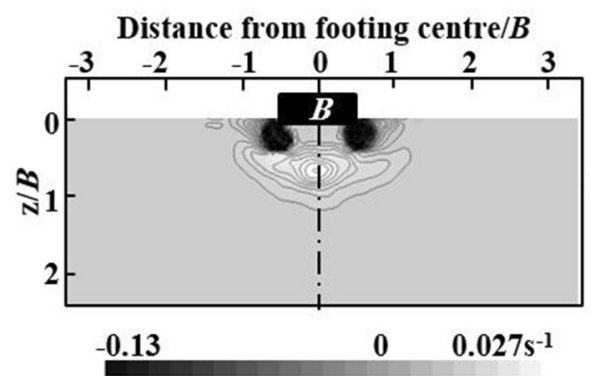

(c) Type 2

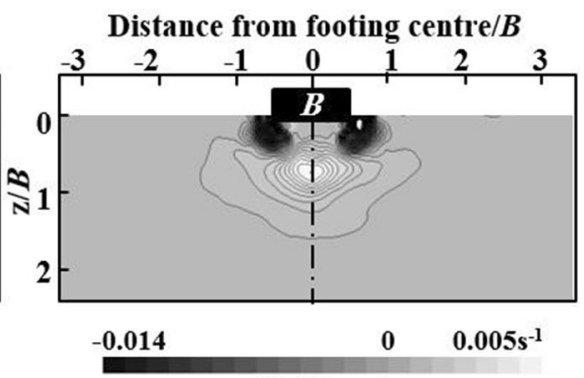

(b) Type 1

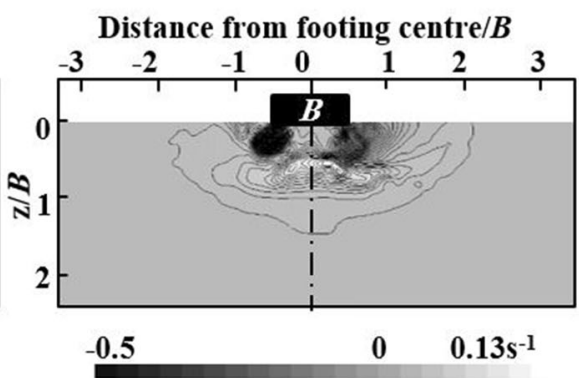

(d) Type 3 ultimate load for the quasi-static and cyclic loading conditions. The maximum shear strain rate $\left(\dot{\gamma}_{\max }\right)$ is derived from the velocity fields as:

$\dot{\gamma}_{\max }=\frac{1}{2}\left(\mathrm{~J}+\mathbf{J}^{T}\right)$

where $\mathrm{J}=S_{R x^{\prime} \mathrm{y}^{\prime}}$ is the velocity gradient tensor and $\mathrm{J}^{T}=S_{R x^{\prime} \mathrm{y}^{\prime}}$ where $T$ is the time and $\left(\mathrm{x}^{\prime}, \mathrm{y}^{\prime}\right)$ are orthogonal axes rotated at $\theta$ relative to (x, y) (Hamm et al. 2011; DantecDynamics 2013). The negative value of the maximum shear strain rate can be used to identify vortex cores, while the positive value indicates the areas of the movement where shear is present. For all types of loading considered here, a highly concentrated zone of shearing is seen at the corner of the footing. For the cyclic loading types, the shear strain rate fields are more dominant and of generally higher magnitude than in the case of the quasi-static loading. The spread of the failure pattern (in terms of the magnitude of shear strain rate) has been relatively wider and shallower in the case of cyclic loading than in the case of the quasi-static loading (Fig. 5).

\subsubsection{Variation of the Vertical and Horizontal Displacements in the Sand Bed}

The differences in the response of displacements between the quasi-static and the cyclic loading tests under the ultimate load are further investigated by plotting the vertical displacement profiles along the line of symmetry of the footing and presented in Fig. 8a. Similarly, the horizontal displacement profiles at a horizontal cross section $0.5 B$ (Jahanger et al. 2018a) below the footing are presented under the ultimate load and presented in Fig. 8b. The vertical displacement profiles show a nonlinear response for all cases of loading. They gradually decrease to a negligible value beyond $\sim z / B=2.0-2.5$ for all cases of the loading. The normalised vertical displacement $\left(S_{\vee} / B\right)$ attains the peak at a depth of about $0.1 B$ for the footing under quasi-static loading and about $0.15 B$ for the cyclic loading.

The profiles of $S_{h}$ component presents $S$-like shape in which the neutral point ( $\sim$ zero value) is confirmed as occurring along the line of symmetry of the footing. The sand along the vertical line of symmetry is confined by the maximum vertical displacement and therefore $S_{h} \sim 0$. The $S_{v}$ and $S_{h}$ components in all types of the cyclic loading exhibit larger values than in the case of the quasi-static loading along the line of symmetry of the footing. This highlights the change in mechanism failure between the cyclic loading types and the quasi-static loading. The $S_{v}$ and $S_{h}$ components variations are relatively higher in the case of type 3 loading. 


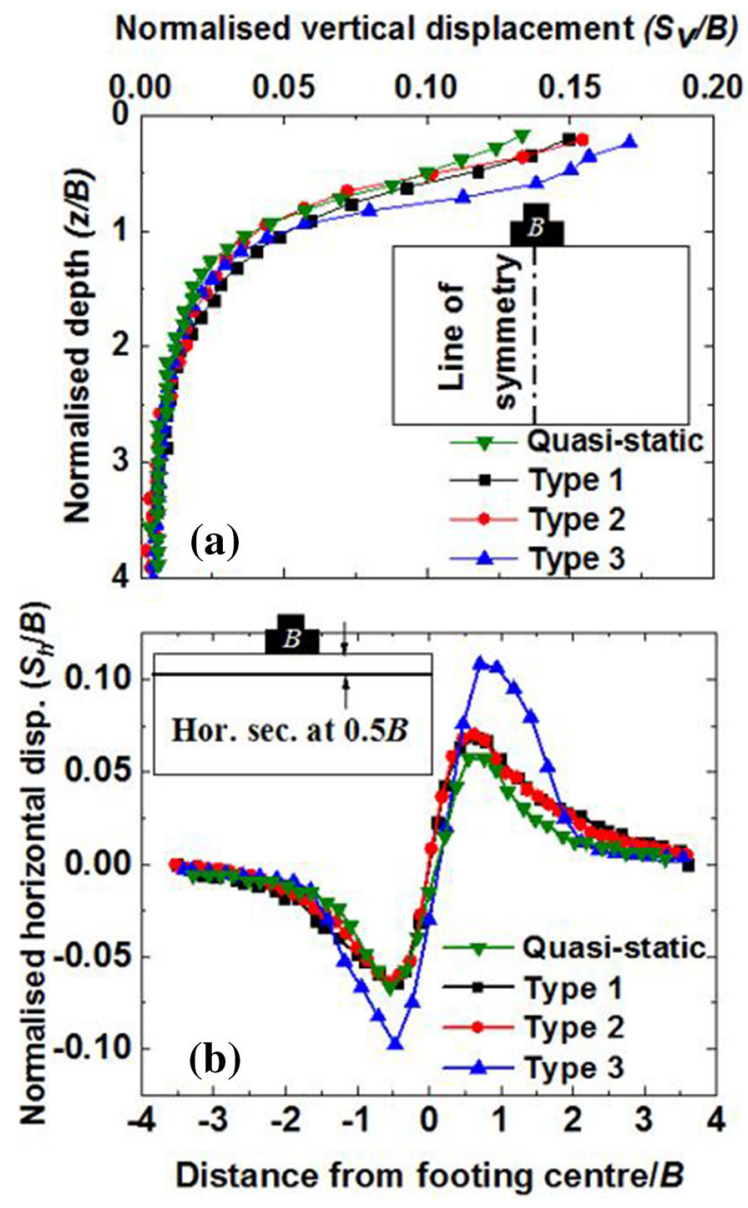

Fig. 8 a Normalised vertical displacement component profiles with depth $\mathrm{z}$ from the bottom surface of the footing, $\mathbf{b}$ normalised horizontal displacement component at a horizontal cross section $0.5 B$ below footing

\subsection{Comparison of the Displacement Fields Obtained from FEM and DPIV}

To understand on the level of agreements between the local scale granular displacements with that of from the FEM simulations, different displacement fields are presented in Fig. 9 for the footing interacting with the dense sand packing under the ultimate load for all cases of loading considered here. The results are presented for a width of $2.5 \mathrm{~B}$ from the edge of the footing (one-half portion is shown for the comparison purposes) as the far-field displacements $(>2.5 B)$ are generally considered as unimportant in the foundation engineering designs of footing-sand interactions. The variation of DPIV-based resultant displacement profiles are presented on the left-hand side (LHS) and compared with the FEM (ANSYS) analysis on the right-hand side (RHS) in this plot.

It is evident that, in general, a good level of agreement between the FEM and DPIV based results are obtained both qualitatively (Fig. 9) and quantitatively (Table 4). As mentioned in Sect. 4.1, the ultimate bearing capacity $\left(q_{\text {ult }}\right)$ for quasi-static, Type 1,2 , and 3 loading were calculated experimentally using the load cell of the Instron loading machine. The difference in the value of ultimate load between using experiments and FEM increases with increase in the amplitude of the loading. There seems to be a pattern here: difference goes from $-6 \%$ all the way up to $16 \%$ due to the effects of different types of cyclic loading; and the difference becomes relatively higher with higher amplitude. This can be attributed to the following: DPIV measures particle displacements from which shear band formations and localized deformations can be observed. However, in FEM, the sand bed is modeled as a homogenous continuum media where shear band formation is usually not well captured. Hence, FEM results should be used to compare bulk displacements or strains, not localized ones within the sand bed with those of DPIV results (Table 4). In this regard, the comparison represented here are for the purpose of general information. Furthermore, a good level of detailed quantitative comparisons between the current FEM and DPIVbased results on the variation of the normalised vertical displacement component $S_{v} / B$ and the normalised horizontal displacement component $S_{h}$ l $B$ along a horizontal section at a depth of $0.5 B$ below the level of footing under the ultimate load were provided for different packing densities of sand under quasi-static loading (Jahanger et al. 2018a).

The magnitude of the horizontal displacement is relatively higher in the case of cyclic loading type 3 than in the quasi-static loading (in which vertical soil displacements tend to dominate). This is due to the increasing spread of the active zones in the failure envelopes that pushed outward and upward to the ground surface as confirmed by DPIV here. The DPIV analyses suggest a classical general shear failure mechanism in the dense sand a deeper and wider distribution of the dead zone region under the cyclic loading types. Cyclic loading types have considerable effect on the ultimate load, settlement components and the failure patterns occurring beneath the footing, especially under the type 3 loading. 
Fig. 9 Resultant

displacement contour field from the DPIV experiments (left) and the corresponding contours using the FEM simulations (right)

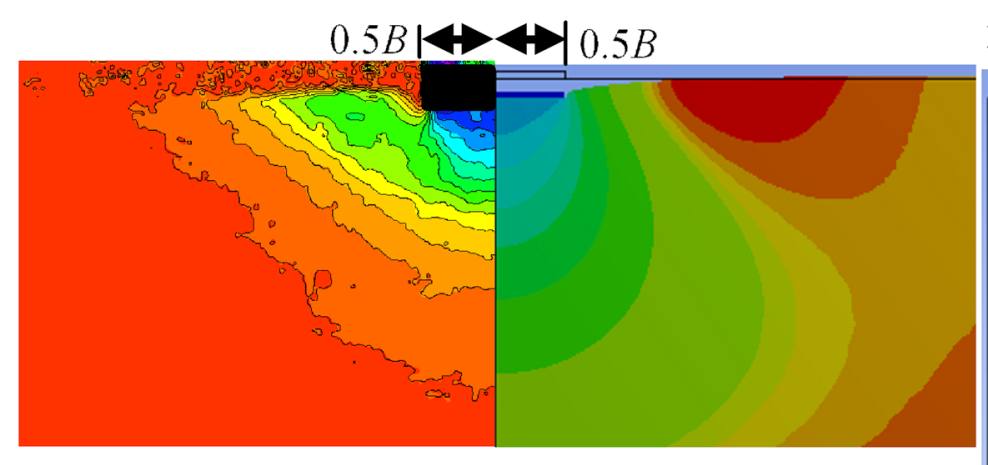

$\mathbf{m m}$

(a) Quasi-static

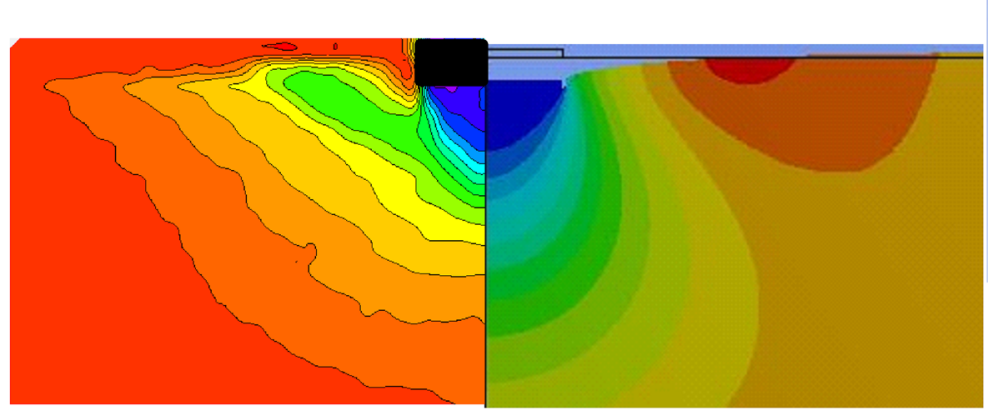

(b) Type 1

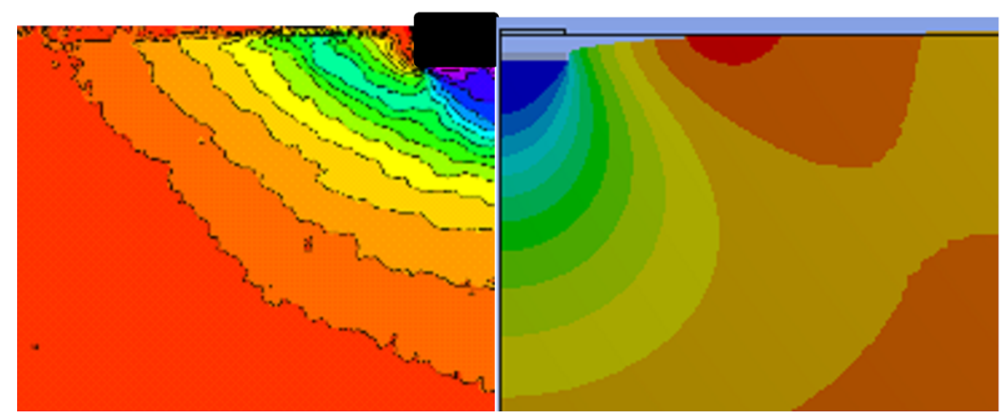

(c) Type 2

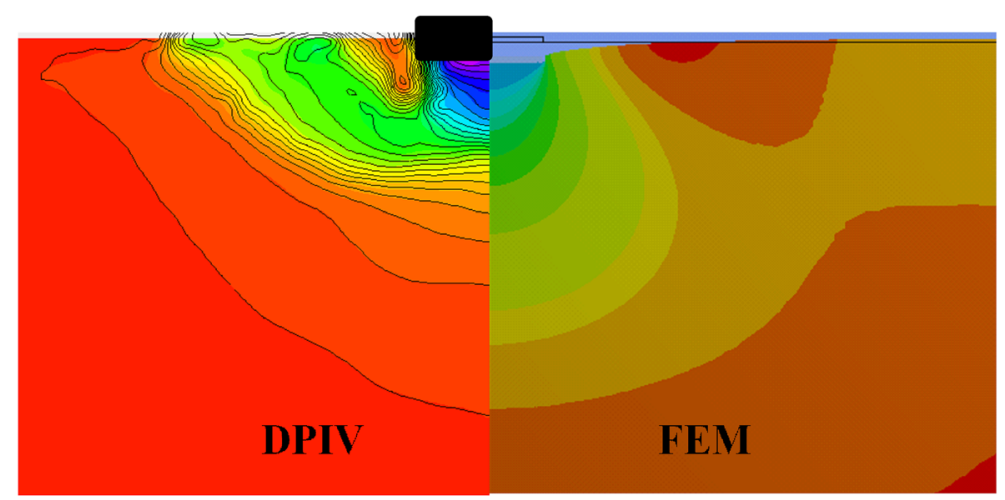

(d) Type 3
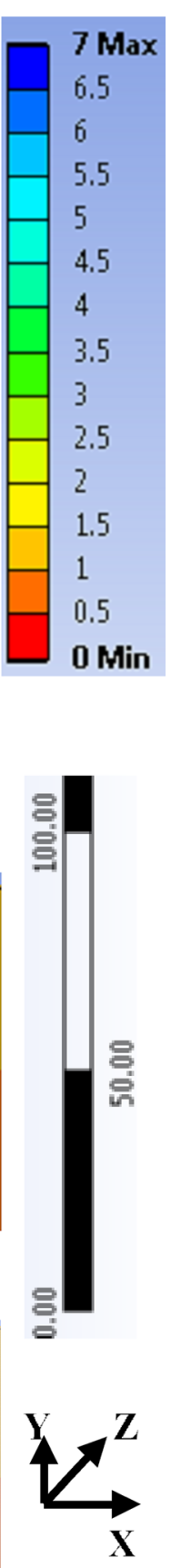
Table 4 Comparison of the ultimate load obtained from the FEM and DPIV experiments

\begin{tabular}{llll}
\hline Tests & Ultimate load $P_{\text {ult }}(\mathrm{N})$ & FEM & ${\text { Difference } \%^{\text {a }}}^{$\cline { 2 - 4 }$}$ \\
\cline { 2 - 4 } & Current DIPV experiments & 229 & -6.15 \\
\hline Quasi-static & 244 & 214 & -9.7 \\
Type 1 & 237 & 273 & +9.6 \\
Type 2 & 249 & 294 & +16.2 \\
Type 3 & 253 & \\
\hline
\end{tabular}

$(+)$ Overestimated, $(-)$ underestimated

${ }^{\mathrm{a} D i f f e r e n c e}(\%)=(($ FEM - Exp. $) /$ Exp. $) \times 100$

Overall, the study validates well the results on the local scale load-displacement of the sand bed obtained from FEM with that of from the experiments using DPIV. Implementing the user-defined defined constitutive relation (global stress-strain curve) of the sand with realistic experimental characterisation measurements is noted as advantageous in modelling the sandfooting interaction problems under different types of loading, including the cyclic loading conditions. It is to be emphasised that the displacements of sand grains measured using DPIV are not fed as an input to FEM simulations. Rather, they are used to compare with corresponding outputs from the FEM simulations, and a good level of agreement is obtained between them. The simplicity in the implementation of (global scale results from load-displacement behavior) the experimentally characterised constitutive relation of the sand grains as an input to FEM simulations can be extended easily in future for large-scale simulations and this could be more advantageous when compared with applying DEM in such studies which is currently difficult.

\section{Conclusions}

In this study, DPIV and FEM simulations are applied coherently to understand the local and global geomechanical characteristics of an axially loaded rigid strip footing interacting with dense sand granular media under the commonly occurring types of cyclic loading conditions. The results are also compared with the case of footing under the quasi-static loading. It is shown that the displacement patterns in the sand bed can be visualized and quantified well using the DPIV under the cyclic loading environments. Local scale information on the vertical and horizontal displacements, vorticity and maximum shear strain rate in the sand bed sheds lights on the evolution of the failure envelope and its characteristics under the ultimate load. Failure surfaces of the homogeneous dense sand under the ultimate load for the quasi-static loading are consistent with Terzaghi (1943), but the advanced measurements reported here also illustrates such results for the sand bed under the cyclic loadings. The boundaries of the zone of plastic flow in the dense sand under the cyclic loads at failure load are spread much wider but shallower when compared with that of under the quasi-static loading. This is due to the increase in the width of the active zones that pushed the sand grains outward and upward to the ground surface relatively more under the cyclic loading as confirmed by DPIV here. The DPIV analyses show a general shear failure in the dense sand for all types of loading considered here. Overall, the deformation behavior of sand bed is sensitive to the type of the loading considered here. Significantly, for the cyclic loading conditions considered here, a good level of agreement is obtained between the results of the local scale displacements fields measured using DPIV and the corresponding FEM simulations in which userdefined, experimentally measured constitutive behavior is fed as an input. Applying such a methodology would be advantageous, especially for modelling the mechanical behavior of sand media by the practicing engineers and scientists in the field of geotechnical and foundation engineering. Further investigations are required, for example to understand the effects of other types of loading environments and scaling effects on the local and global geomechanical characteristics in granular sand-structure interaction problems. 
Acknowledgements Z.K. Jahanger acknowledges the Ministry of Higher Education and Scientific Research (MOHESR), Republic of Iraq and the University of Baghdad for the doctorate scholarship (Grant No. 2075).

Open Access This article is distributed under the terms of the Creative Commons Attribution 4.0 International License (http:// creativecommons.org/licenses/by/4.0/), which permits unrestricted use, distribution, and reproduction in any medium, provided you give appropriate credit to the original author(s) and the source, provide a link to the Creative Commons license, and indicate if changes were made.

\section{References}

Adrian RJ (1991) Particle-imaging techniques for experimental fluid mechanics. Ann Rev Fluid Mech 23:261-304

Albaraki S, Antony SJ (2014) How does internal angle of hoppers affect granular flow? Experimental studies using digital particle image velocimetry. Powder Technol 268:253-260

Altaee A, Fellenius BH (1994) Physical modeling in sand. Can Geotech J 31:420-431

Andersen KH (2009) Bearing capacity under cyclic loadingoffshore, along the coast, and on land. Can Geotech J 46:513-535. https://doi.org/10.1139/T09-003

ANSYS (2016) ANSYS theory manual. ANSYS Inc, Canonsburg

Antony SJ (2007) Link between single-particle properties and macroscopic properties in particulate assemblies: role of structures within structures. Philos Trans R Soc A Math Phy Eng Sci 365(1861):2879-2891

Armin A, Fotouhi R, Szyszkowski W (2014) On the FE modeling of soil-blade interaction in tillage operations. FE Anal Des 92:1-11

Asakereh A, Ghazavi M, Tafreshi SM (2013) Cyclic response of footing on geogrid-reinforced sand with void. Soils Found 53(3):363-374

ASTM (1989) Soil and rock, building, stores, geotextiles. American Society for Testing and Materials, ASTM Standard. 04.08, West Conshohocken

Bowles JE (1996) Foundation analysis and design, 5th edn. McGraw-Hill, Singapore

Cerato B, Lutenegger AJ (2007) Scale effects of shallow foundation bearing capacity on granular material. J Geotech Geoenviron Eng 133:1192-1202

Cundall PA, Strack OD (1979) A discrete numerical model for granular assemblies. Geotechnique 29(1):47-65

DantecDynamicsA S (2013) DynamicStudio user's guide. Dantec Dynamics, Skovlunde

Das BM (2009) Shallow foundations: bearing capacity and settlement. CRC Press, London

Das BM (2018) Principles of foundation engineering, 8th edn. Cengage Learning, Mumbai

Das BM, Shin EC (1996) Laboratory model tests for cyclic loadinduced settlement of a strip foundation on a clayey soil. Geotech Geol Eng 14(3):213-225
Dijkstra J, Gaudin C, White DJ (2013) Comparison of failure modes below footings on carbonate and silica sands. Int $\mathrm{J}$ Phys Model Geotech 13(1):1-12

Gollin D, Brevis W, Bowman ET, Shepley P (2017) Performance of PIV and PTV for granular flow measurements. Granul Matter 19(3):42. https://doi.org/10.1007/s10035017-0730-9

Gordan B, Adnan A, Aida MA (2014) Soil saturated simulation in embankment during strong earthquake by effect of elasticity modulus. Model Simul Eng. https://doi.org/10. 1155/2014/191460

Hamm E, Tapia F, Melo F (2011) Dynamics of shear bands in a dense granular material forced by a slowly moving rigid body. Phys Rev E 84:041304

Head KH (2006) Manual of soil laboratory test: soil classification and compaction tests, vol 1. CRC Press, Boca Raton

Jahanger ZK (2018) Micromechanical investigations of foundation structures-granular soil interactions. PhD thesis, University of Leeds

Jahanger ZK, Antony SJ (2017a) Application of digital particle image velocimetry in the analysis of scale effects in granular soil. In: Proceedings of the 19th international conference on soil mechanics and dynamics, Rome, 9(7) part X, pp 1134-1139

Jahanger ZK, Antony SJ (2017b) Application of particle image velocimetry in the analysis of scale effects in granular soil. Int J Civ Environ Struct Constr Archit Eng 11(7):910-915

Jahanger ZK, Antony SJ, Richter L (2016) Displacement patterns beneath a rigid beam indenting on layered soil. In: 8th Americas regional conference of the international society for terrain vehicle systems, Michigan

Jahanger ZK, Sujatha J, Antony SJ (2018a) Local and global granular mechanical characteristics of grain-structure interactions. Ind Geotech J 48(4):753-767

Jahanger ZK, Antony SJ, Martin E, Richter L (2018b) Interaction of a rigid beam resting on a strong granular layer overlying weak granular soil: multi-methodological investigations. J Terramech 79:23-32

Kumar J, Bhoi MK (2009) Interference of two closely spaced strip footings on sand using model tests. J Geotech Geoenviron Eng 135(4):595-604

Kumar J, Kouzer K (2007) Effect of footing roughness on bearing capacity factor $\mathrm{N} \gamma$. J Geotech Geoenviron Eng 133(5):502-511

Lee H-H (2015) Finite element simulations with ANSYS workbench 16. SDC Publications, Kansas

Liu C, Evett JB (2004) Soils and foundations, 6th edn. Pearson Prentice Hall, New Jersey

Mosadegh A, Nikraz H (2015) Bearing capacity evaluation of footing on a layered soil using ABAQUS. J Earth Sci Clim Change 6(3): 1000264

Murthy TG, Gnanamanickam E, Chandrasekar S (2012) Deformation field in indentation of a granular ensemble. Phys Rev E 85:061306

Nguyen N-S, François S, Degrande G (2014) Discrete modeling of strain accumulation in granular soils under low amplitude cyclic loading. Comput Geotech 62:232-243

O’Loughlin C, Lehane B (2010) Nonlinear cone penetration test-based method for predicting footing settlements on sand. J Geotech Geoenviron Eng 136(3):409-416 
Peralta P (2010) Investigations on the behavior of large diameter piles under long-term lateral cyclic loading in cohesionless soil. IGtH, Hannover

Potts DM, Zdravkovic L (2001) Finite element analysis in geotechnical engineering: application. Thomas Telford, London

Raymond GP (2002) Reinforced ballast behaviour subjected to repeated load. Geotext Geomembr 20(1):39-61

Raymond GP, Komos FE (1978) Repeated load testing of a model plane strain footing. Can Geotech J 15(2):190-201

Sabbar A, Chegenizadeh A, Nikraz H (2016) Review of the experimental studies of the cyclic behaviour of granular materials: geotechnical and pavement engineering. Aust Geomech J 51(2):89-103

Salem M, Elmamlouk H, Agaiby S (2013) Static and cyclic behavior of North Coast calcareous sand in Egypt. Soil Dyn Earthq Eng 55:83-91

Shajarati A, Sørensen KW, Nielsen SK, Ibsen LB (2012) Behaviour of cohesionless soils during cyclic loading. Department of Civil Engineering, Aalborg University, Aalborg
Tafreshi SM, Dawson A (2012) A comparison of static and cyclic loading responses of foundations on geocell-reinforced sand. Geotext Geomembr 32:55-68

Tafreshi SM, Mehrjardi GT, Ahmadi M (2011) Experimental and numerical investigation on circular footing subjected to incremental cyclic loads. Int J Civ Eng 9(4):265-274

Terzaghi K (1943) Theoretical soil mechanics. Wiley, New York

Terzaghi K, Peck RB (1967) Soil mechanics in engineering practice, 2nd edn. Wiley, New York

Thornton C, Antony SJ (1998) Quasi-static deformation of particulate media. Philos Trans R Soc Lond Ser Math Phys Eng Sci 356:2763-2782

Vesic AS (1973) Analysis of ultimate loads of foundations. Soil Mech Found Div 99(SM1):45-73

White D, Tak W, Bolton M (2004) Soil deformation measurement using particle image velocimetry (PIV) and photogrammetry. Geotechnique 53(7):619-631

Publisher's Note Springer Nature remains neutral with regard to jurisdictional claims in published maps and institutional affiliations. 